\title{
On the preparation and characterization of thin NiTi shape memory alloy wires for MEMS
}

\author{
Riccardo Casati, Maurizio Vedani \\ Department of Mechanical Engineering, Politecnico di Milano, Via La Masa 34, Milano, Italy
}

Syed A. M. Tofail, Calum Dikinson

Materials and Surface Science Institute, University of Limerick, Limerick, Ireland

Ausonio Tuissi

National Research Council (CNR-IENI), Corso Promessi Sposi 29, Lecco, Italy

\begin{abstract}
Shape memory alloy (SMA) wires are employed as actuators in small devices for consumer electronics, valves and automotive applications. Because of the continued miniaturization of all the industrial products, nowadays the tendency is to produce MEMS (micro electromechanical systems). Among the most promising functional MEMS materials, the thin SMA wires that are offering a rapid actuating response with high power/weigh ratio of the material, are attracting a world wide interest. This paper is aimed at showing the production process and the characterizations of thin NiTi shape memory wires. The activity was focused on drawing procedure and on functional and TEM characterizations of the final products. In particular, it was evaluated the performance of the SMA wires for actuators in terms of functional fatigue and thermo-mechanical properties by means of an experimental apparatus design ad hoc for these specific tests.
\end{abstract}

KEYWORDS. Shape memory alloys; SMA; MEMS; Thin wire; Actuators; TEM.

\section{INTRODUCTION}

$\mathrm{S}$ MAs are basically functional materials which exhibit peculiar thermo-mechanical properties such as the Shape Memory Effect and the Superelasticity. These properties are consequence of a reversible thermo-elastic martensitic transformation occurring at the solid state [1]. Because the martensite phase shows a strong amplitude-dependent internal friction, SMA have also an high damping capacity [2,3]. When SMA is used as actuator, it can be classified as "Smart Material" because it combines both sensor and actuator functions. SMA alloys are applied with success in several commercial fields: biomedical (stents, orthodontic arc wire, orthopaedics devices, surgical tools); sensor/actuator (valves, active actuators, on/off devices); coupling (pipe fastener, electric fastener); sport; manufactures; antennas, gadgets etc. [4,5]. In the modern world, great emphasis has been placed in miniaturization and huge research efforts are oriented to develop MEMS (Micro Electro-Mechanical Systems) to perform a multitude of tasks [6]. Among MEMS materials the SMA, in form of films or thin wires, are attracting a particular interest for the development of new highly functionalized devices on micro/meso scale [7-10]. SMA elements are characterized by a significant amount of actuation with an extremely small total volume over conventional actuator mechanisms. Another advantage that shape memory alloys have is the versatility since they can be actuated thermally or electrically [7-10]. In this work, Ti rich NiTi alloy, with high transformation temperatures, is produced by vacuum induction melting and thin wire are manufactured by hot and cold working. The main processing aspects of thin NiTi wire manufacturing are reported with specific reference to the effect 
of cold drawing steps on the wire characteristics. The process can be scale down to diam. 10 micron wire for the developing of SMA device within meso/micro scale. For both the drawn and the trained wires, longitudinal cracks, localized around inclusions, were highlighted by TEM analyses. Again, functional properties of the produced wires are studied by both DSC scans and electrically actuated thermal cycling under constant applied stress up to 300.000 cycles.

\section{EXPERIMENTAL METHODS}

$\mathrm{I}$ $\mathrm{t}$ was chosen a $\mathrm{Ni}$ rich $\mathrm{Ni}_{49} \mathrm{Ti}_{51}$ (at.\%) composition, which is very commonly employed for the production of shape memory materials for actuators with transformation temperature above room temperature. Electrolytic grade nickel and pure titanium (Grade 1) were melted by VIM (Vacuum Induction Melting) furnace in carbon crucible under argon atmosphere [11]. The ingot was hot forged and hot rolled at $950^{\circ} \mathrm{C}$ and finally cold drawn with intermediate annealing. The first steps of the drawing process (down to the diameter of $0.5 \mathrm{~mm}$ ) were performed by means of a conventional drawing machine reaching values of area reduction of about $10-20 \%$ before each thermal annealing $\left(700{ }^{\circ} \mathrm{C}\right)$. The final steps of drawing were indeed carried out employing a special experimental drawing system (MGS mod. TRF $6 / 25 \mathrm{M}$ ) modified to prevent breakings of wires (Fig. 1a). This machine was equipped by a controlled drawing speed system, an electrical clutch coiler and a laser sensor-controlled spooling system for correct distribution of the wire on the spool (Fig. 1b), diamond dies, load cell, die cooling system, camera for checking correct wire pay-on (Fig. 1b). In Tab. 1, the die used and the heat treatments parameters carried out during the cold drawing process are resumed. The evolution of functional properties, in particular of the residual strain, during thermo-mechanical cycling by means of an experimental apparatus designed ad hoc for these specific tests is here reported. Specimens (100 mm in length) were vertically gripped in the testing equipment and axially loaded $(250 \mathrm{MPa})$. They were heated by electrical pulses (see Fig. 2 for details of pulse parameters) and cooled by natural air convection. The wire displacement was measured by LVDT and relative strain was continuously monitored and evaluated as $\Delta \mathrm{L} / \mathrm{Lo}$ (Lo wire length for each cycle before heating). The same experimental apparatus detailed reported elsewhere [13] was used in order to carried out the first 500 thermal cycles under $250 \mathrm{MPa}$ as well as fatigue tests under $200 \mathrm{MPa}$. For the latter the total recovered strain was set at $3.8 \%$ and the stress at $200 \mathrm{MPa}$.

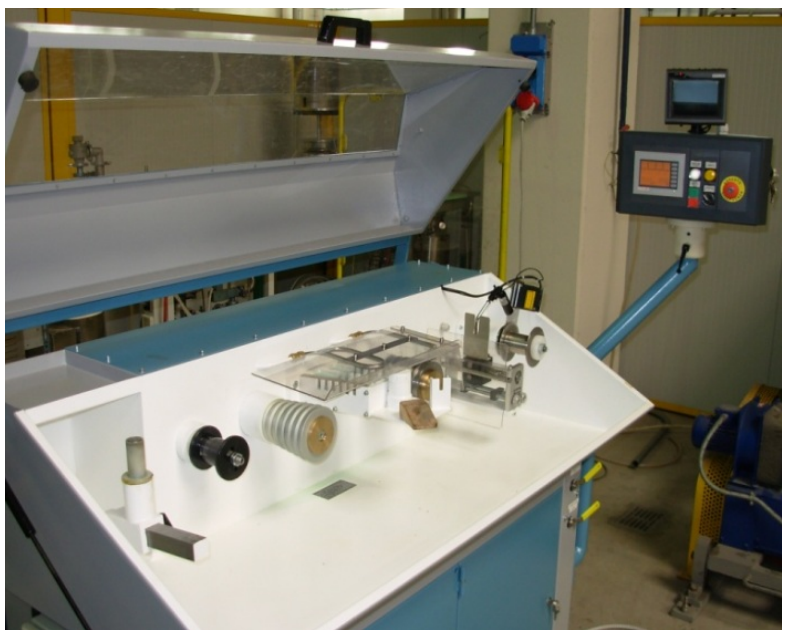

(a)

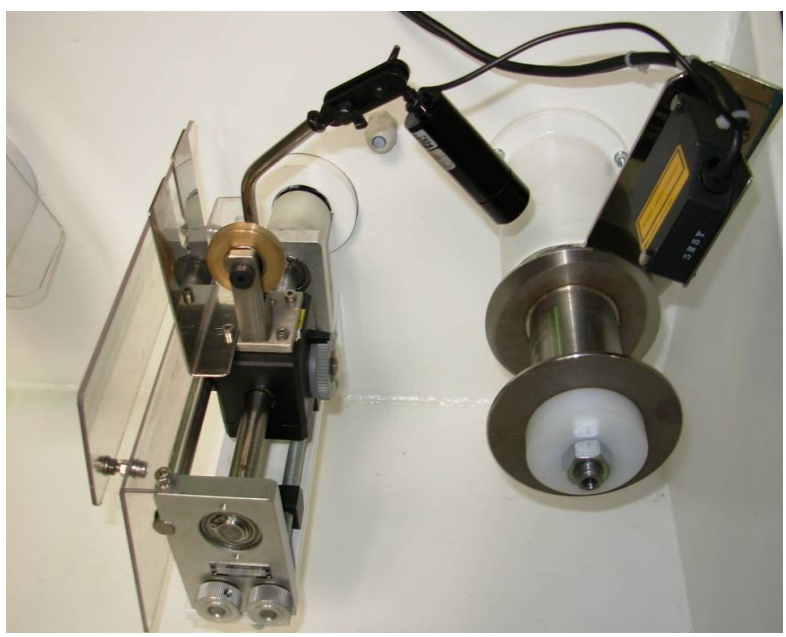

(b)

Figure 1: a) Experimental drawing system b) laser sensor-controlled spooling system for correct distribution of the wire on the spool and camera for checking correct wire pay-on .

Before and after thermo-mechanical cycling calorimetric test were carried out by DSC Seiko 220C. The temperature range investigated was $223 \mathrm{~K} / 403 \mathrm{~K}\left(-50^{\circ} \mathrm{C} / 130^{\circ} \mathrm{C}\right)$. Thermo-mechanical loop was performed by DMA TA Q800 equipped with tension clamps for uniaxial tests. The temperature range investigated was $273 \mathrm{~K} / 423 \mathrm{~K}\left(0^{\circ} \mathrm{C} / 150^{\circ} \mathrm{C}\right)$, the heating and cooling rate was $5 \mathrm{~K} / \mathrm{min}$ and the applied stress was $200 \mathrm{MPa}$. Microstructural analysis was executed by JEOL JEM-210 operating at $80-200 \mathrm{kV}$. Thin slice for TEM investigation were extracted from the center of the wire by Focus Ion Beam FEI 200 (Fig.3a). In Fig.3b a picture of a thin slice FIB cutting is depicted. 


\begin{tabular}{cc}
\hline $\begin{array}{c}\phi \text { Die }(\mu \mathrm{m}) \\
200\end{array}$ & Area reduction \\
- & - \\
Heat treatment: $300 \mathrm{~s} 5$ & $50^{\circ} \mathrm{C}+$ Water Quenching \\
\hline 175 & $23,4 \%$ \\
150 & $26,5 \%$ \\
Heat treatment: $300 \mathrm{~s} 550^{\circ} \mathrm{C}+$ Water Quenching \\
\hline 130 & $24,9 \%$ \\
110 & $28,4 \%$ \\
Heat treatment: $300 \mathrm{~s} 550^{\circ} \mathrm{C}+$ Water Quenching \\
\hline 100 & $17,4 \%$ \\
90 & $19,0 \%$ \\
80 & $21,0 \%$ \\
Heat treatment: $1200 \mathrm{~s} 400^{\circ} \mathrm{C}+$ Water Quenching \\
\hline
\end{tabular}

Table 1: Drawing steps and corresponding area reduction.

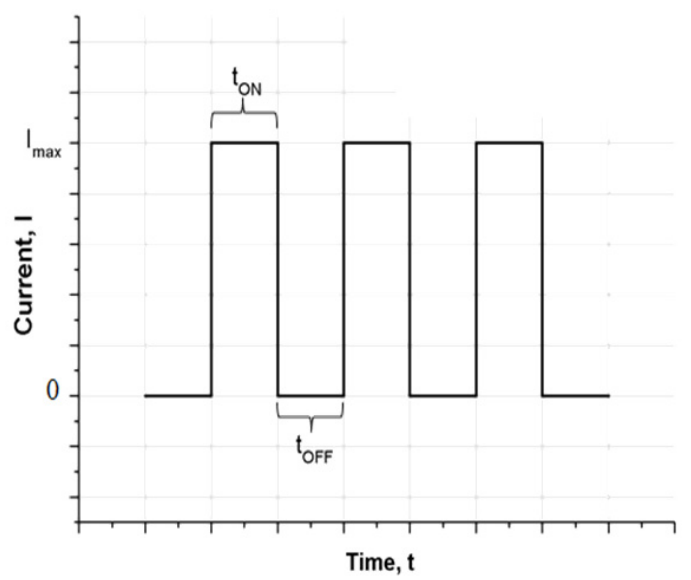

Figure 2: Step waveform electrical pulse: $\mathrm{t}_{\mathrm{ON}}=0,4 \mathrm{~s}, \mathrm{t}_{\mathrm{OFF}}=2,5 \mathrm{~s}, \mathrm{I}_{\mathrm{MAX}}=0.13 \mathrm{~A}$
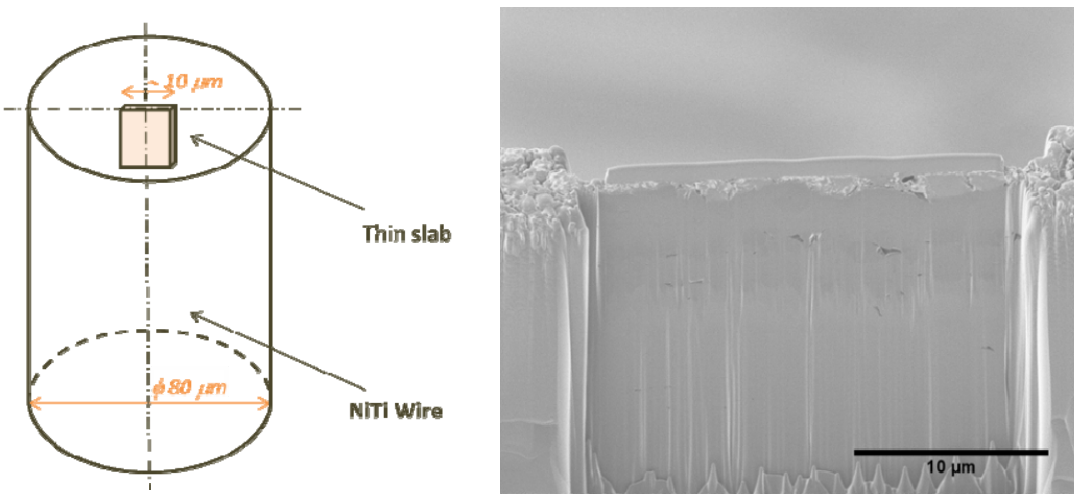

Figure 3: a) Scheme of TEM sample preparation. b) NiTi thin slice used for TEM analysis.

\section{RESULTS}

he whole working process was carried out without any formation of macroscopic cracks on the surfaces of the bars and the wires. The microstructure of the final product $\left(80 \mu \mathrm{m}\right.$ wire) after heat treatment $\left(400^{\circ} \mathrm{C}, 1200 \mathrm{~s}\right)$ was investigated by TEM. This analysis revealed a very fine polycrystalline microstructure (grain size was about 20nm) and the presence of inclusions (Fig.4). 

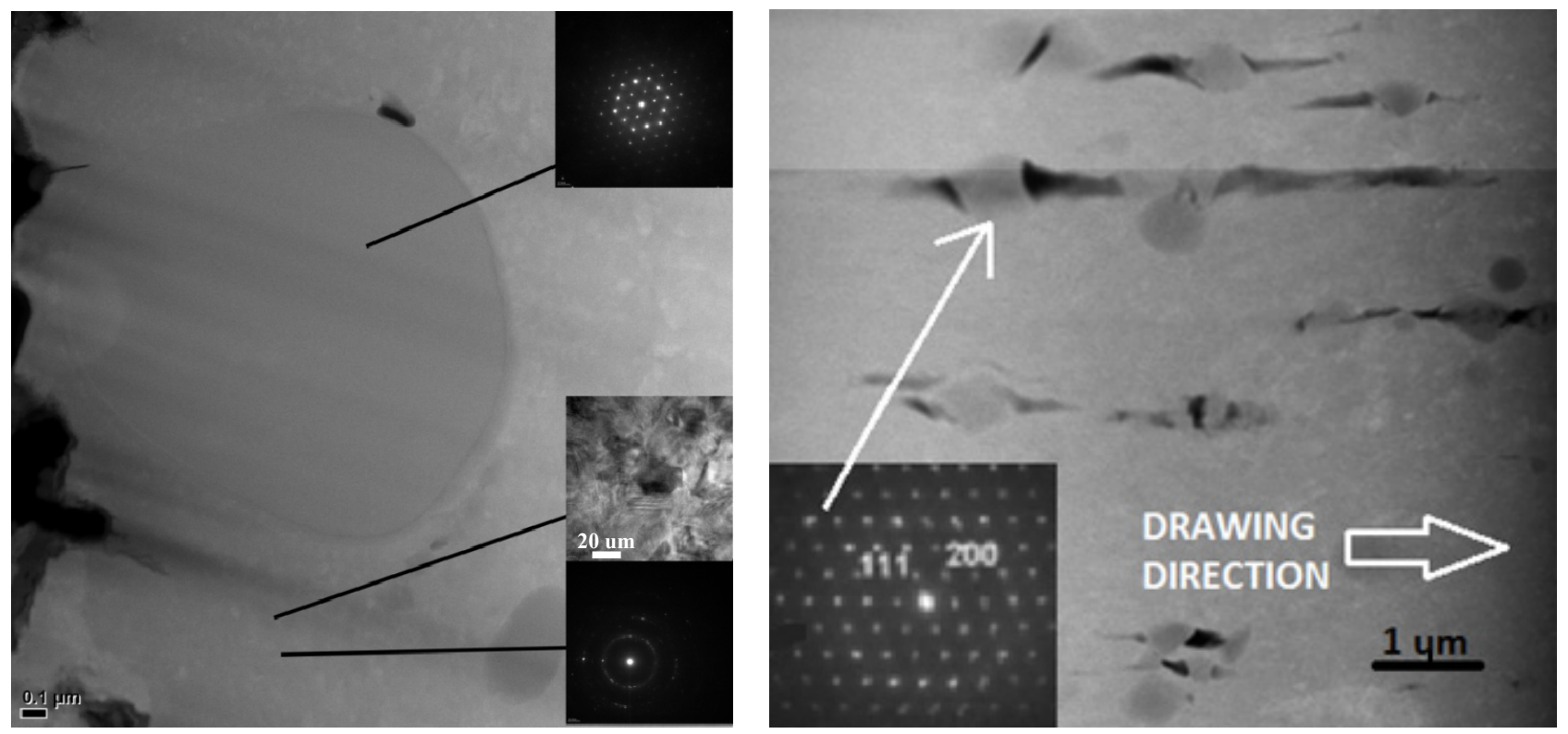

Figure 4: TEM images of the wire after the last heat treatment $\left(1200 \mathrm{~s}, 400^{\circ} \mathrm{C}\right)$.

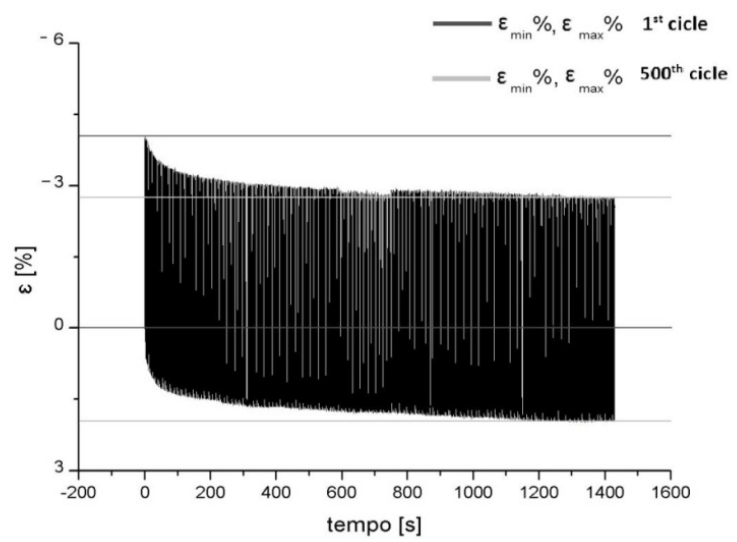

Figure 5: Thermal cycling under constant stress (250MPa). This process is performed to stabilize the SM properties of the material.

A high content of $\mathrm{Ti}_{4} \mathrm{Ni}_{2} \mathrm{O}_{\mathbf{x}}$ confirmed by selected area electron diffraction (SAED) were observable. The drawing procedures caused the breaking of these ceramic compounds into fine inclusions that lined up in the drawing direction inducing significant amount of cracks into the matrix (Fig.4). The inset diffraction pattern indexed space group Fd-3m and lattice parameter $1.19 \mathrm{~nm}$ viewed down the [01-1] zone axis (in this respect, see the previous work by Tuissi and coworkers [12]). Before their application, SMAs must be thermo-mechanical cycled to stabilize their functional properties [13]. In order to reproduce a standard process of stabilization of the material, 500 thermal cycles under an applied stress of $250 \mathrm{MPa}$ were carried on the wires (Fig.5). During the first few hundreds cycles, the material accumulates irreversible plastic deformation. From the curve in Fig. 5 the lengthen of the wire is noticeable (about $2 \%$ ). This phenomenon involves the increase of transition temperatures. Fig.6a shows the results of calorimetric analyses performed on two samples of the wire taken before and after the thermo-mechanical cycling. Both the samples exhibit a single-stage inverse transformation (between B19' and B2) and a two-stage direct transformation (from B2 to R-phase and then to B19'). The main gap between the two curves consists in the transformation peaks broadening and in a increasing of transition temperature due to the cycling. Similar results were obtained by thermal loop under constant stress (200 MPa) by DMA. As depicted in Fig.6b, the T- $\varepsilon$ curves show a double inflexion on the cooling branch due to a two-stage direct transformation. The load leads to an increase in all transition temperatures, this is in according with the Clausius-Clapeyron relationship [1]. The increase in transformation temperature due to thermo-mechanical cycling is detectable even under an applied constant load. The cycling promoted an increase of $\mathrm{R} \rightarrow \mathrm{M}$ transition temperature which, summed to the effect of the applied load, implies the disappearance of R-phase during the cooling and then a narrow thermal hysteresis. 
In Fig. 7 the strain-cycles curves are reported: the wire was subjected to 300,000 cycles under constant stress (200 MPa) and the strain recovered was set at $3.8 \%$. This fatigue test shows that even if the metal matrix exhibits a significant amount of cracks, the wire could withstand a very high number of thermo-mechanical cycles, indeed no wire failure occurred.

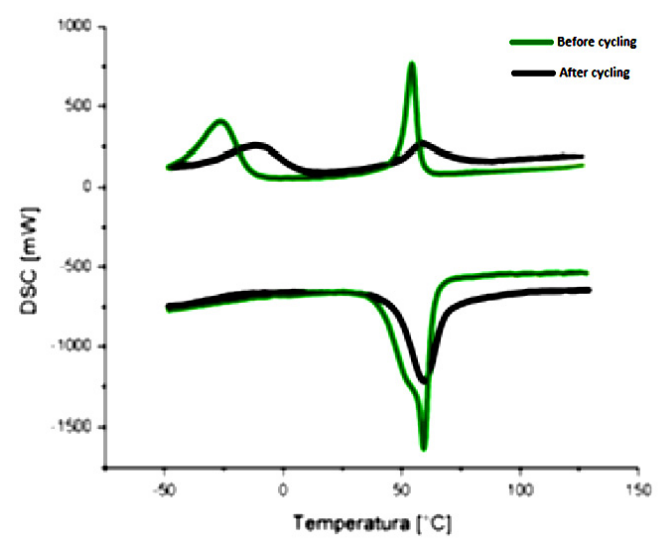

(a)

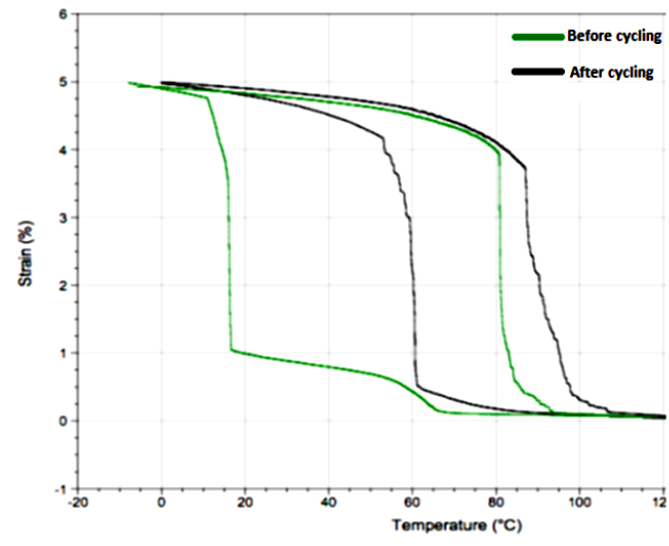

(b)

Figure 6: a) DSC curves and b) Thermal loop under constant load before and after 500 cycles

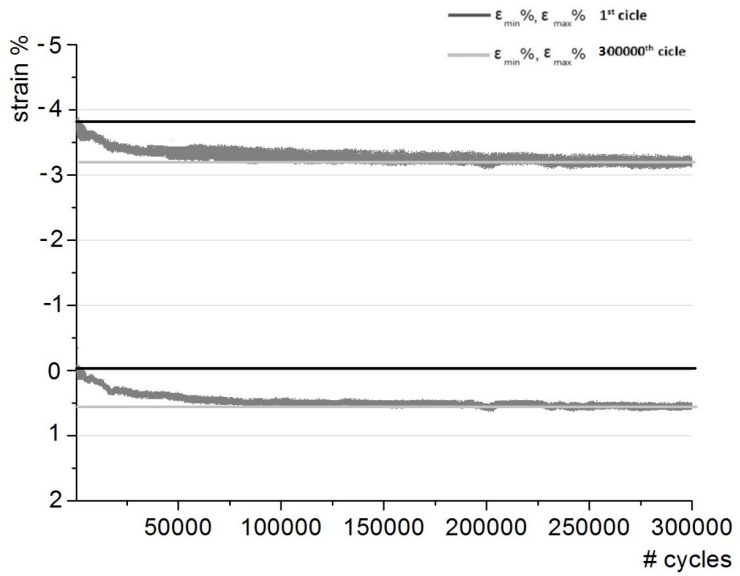

Figure 7: Fatigue test: thermal cycling under constant stress (200 MPa).

\section{CONCLUSIONS}

$\checkmark$ he results obtained through this research can be summarized as follow:

$\checkmark 80 \mu \mathrm{m}$ Ni49Ti51 (at.\%) wire was produced without any formation of macroscopic cracks on the surfaces of the final product. Then, the procedure revealed to be suitable for the production of very thin shape memory wire employable in MEMS, actuators and other applications.

$\checkmark$ TEM analysis revealed a mean grain size of few tens nanometers and the presence of rather big inclusions (less than 1 $\mu \mathrm{m})$. SAED pattern revealed these particles to be $\mathrm{Ti}_{4} \mathrm{Ni}_{2} \mathrm{O}_{\mathrm{x}}$ inclusions. These ceramic compounds did not impaired significantly the fatigue behavior of the SMA wire, since it could reach 300000 cycles without failing.

$\checkmark$ The wire shows characteristic transformation temperature higher than room one. Thermo-mechanical cycling leads to a reduction of thermal hysteresis. These are good points for the using of the material as shape memory actuator.

\section{ACKNOWLEDGEMENTS}

he authors would like to thanks Marco Pini; Nicola Bennato; Enrico Bassani (CNR IENI Lecco) for melting and technical assistance Serguei Belochapkines (University of Limerick) for TEM assistance. 


\section{REFERENCES}

[1] K. Otsuka, C.M. Wayman, Shape Memory Materials. Cambridge University Press, (1998).

[2] J.Van Humbeek, Journal of Alloys and Compounds, 355(1-2) 30 (2003) 58.

[3] B. Coluzzi, A. Biscarini, G. Mazzolai, F.M. Mazzolai, A. Tuissi, E. Villa, Key Engineering Materials, 319 (2006) 1.

[4] T. Duerig, A. Pelton, D. Stöckel, Materials Science and Engineering A, 273-275 (1999) 149.

[5] J. Van Humbeck, Materials science and Engineering A, 273-275 (1999) 134.

[6] T. Hsu, In: IEEE/ASME International conference on Advanced Manufacturing Technologies and Education in the 21st Century, Chia-Yi, Taiwan, Republic of China, (2002).

[7] K. Ikuta, Micro/miniature shape memory alloy actuator. IEE-ICRA (1990).

[8] L. Sun, W.M. Huang, Z. Ding, Y. Zhao, C.C. Wang, H. Purnawali, C. Tang, Materials and Design 33 (1) (2012) 577.

[9] A. Nespoli, S. Besseghini, S. Pittaccio, E. Villa, S. Viscuso, Sen Actuators, A158 (2010) 149.

[10] Y. Fu, H. Du, W. Huang, S. Zhang, M. Hu, Sensors and Actuators A, 112(2-3) (2004) 395.

[11] A. Tuissi, P. Bassani, A. Mangioni, L. Toia, In: Proceedings SMST 2004, ASM International, Materials Park, OH, (2006) 501.

[12] R. Casati, A. Tuissi, S. Belochapkine, C. Dickinson, S.A.M. Tofail, Functional materials letters, 5(1) (2012) 1250009.

[13] R. Casati, A. Tuissi, Journal of Materials Engineering and Performance, 21(12) (2012) 2633. 